\title{
Surface oxidation studies of Al-2 wt $\%$ Li thin films
}

\author{
V GEETHA and V K VAIDYAN \\ Department of Physics, University of Kerala, Kariavattom 695 581, India \\ MS received 7 November 1988
}

\begin{abstract}
Thin films of Al-2 wt\% Li alloy are prepared on well-cleaned glass substrates by vacuum evaporation at room temperature. Electrical conductivity studies of both alloy $\mathrm{Al}(\mathrm{Li})$ and pure Al films show that they obey the logarithmic rate law during the initial period of oxidation. The addition of lithium, however, increases the oxidation rate considerably during the initial period of oxidation. Surface analysis by laser Raman spectroscopy indicates the existence of $\mathrm{LiO}_{2}$ and $\mathrm{Al}_{2} \mathrm{O}_{3}$ as the most probable oxide components.
\end{abstract}

Keywords. Al(Li) logarithm; electrodes; Raman lines; electropositive; selective oxidation; polycrystalline; amorphous; thermochemical.

\section{Introduction}

$\mathrm{Li}-\mathrm{Al}$ alloys have been extensively investigated for their interesting electronic properties. They have very high ionic conductivity different from that of pure aluminium, and therefore much importance is attached to resistivity change studies of alloy films with time to explain their oxidation behaviour (Kishio et al 1981). The additional metal lithium present in these alloys is said to have significant effect on the oxidation of the alloy as compared to pure aluminium (Kurtasova and Polyanskii 1983).

In this paper we report resistance variation studies of $\mathrm{Al}-2 \mathrm{wt} \% \mathrm{Li}$ thin films with time and as compared to that of pure aluminium thin films. The surface analysis of these films after oxidation is also done using laser Raman spectroscopy.

\section{Experimental}

Thin films of $\mathrm{Al}(\mathrm{Li})$ were prepared by the vacuum evaporation method (pressure $10^{-5}$ torr) into clean Blue star microslides of size $75 \times 14 \times 2.85 \mathrm{~mm}^{3}$. Several samples of about $10 \mathrm{~nm}$ thickness were prepared under the same conditions. Silver electrodes of matching thicknesses were used and the resistance of each film at room temperature was measured using a digital multimeter within a few seconds of starting the oxidation and continued for about $30 \mathrm{~min}$. The experiment was repeated for pure aluminium films.

Using a SPEX RAMALOG-5 spectrometer, the Raman spectra of $\mathrm{Al}(\mathrm{Li})$ thin films oxidized at $303,478,508$ and $533 \mathrm{~K}$ were recorded. The Raman lines were used to identify the oxides present in the film.

\section{Results and discussion}

\subsection{Resistivity studies}

Figure 1 shows the change in resistance with $\log (t)$ of $\mathrm{Al}(\mathrm{Li})$ and $\mathrm{Al}$ thin films, due 


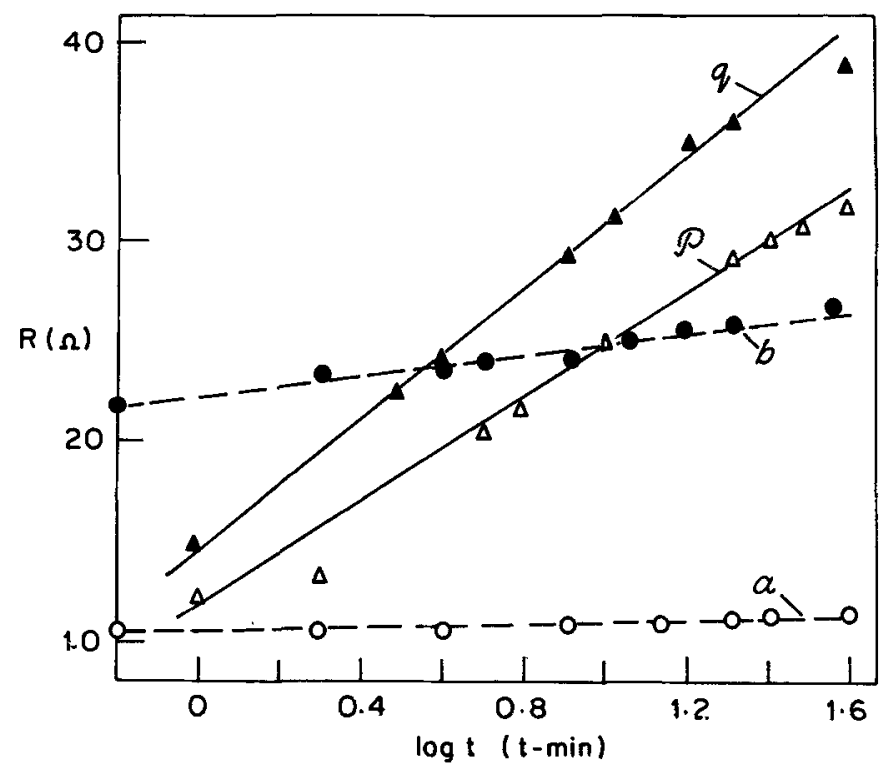

Figure 1. Oxidation kinetics of thin films of $\mathrm{Al}(\mathrm{Li})$ and pure $\mathrm{Al}$ thin films. Al with initial resistance $(a) 10.6$ and $(h) 21.4 \mathrm{ohm}$; $\mathrm{Al}(\mathrm{Li})$ with initial resistance $(p) 12$ and $(q) 14.7 \mathrm{ohm}$.

to oxidation at room temperature for about $30 \mathrm{~min}$. These curves show that for the initial period of oxidation, the resistance varies linearly with the function of $\log$ time.

In the $\mathrm{Al}(\mathrm{Li})$ film, lithium atoms are more active than aluminium atoms due to selective oxidation. The occurrence of oxide film causes an excess of vacancies at the metal oxide boundary. These vacancies diffuse into adjacent areas of the metal. In lithium oxide the self-diffusion coefficient of the $\mathrm{Li}$ ion is smaller than that of the $\mathrm{O}_{2}$ ion and the vacancies are easily saturated with oxygen. Thus, the composition of the alloy determines the oxidation rate (Ando et al 1986). Pure aluminium thin films are polycrystalline and provide numerous grain boundaries (Bhavani and Vaidyan 1979). Diffusion into the boundaries blocks the oxide formation leading to a slower oxide growth rate. Also aluminium is more protective than alkali metals, hence alloys containing more electropositive materials increase oxide growth. Both alloying elements oxidize simultaneously to give $\mathrm{LiO}_{2}$ and $\mathrm{Al}_{2} \mathrm{O}_{3}$, the oxygen pressure in the atmosphere being greater than the equilibrium dissociation pressure of both oxides (Wallwork 1976).

\subsection{Identification of oxides}

The observed Raman shifts at four different temperatures viz. one at room temperature and other three near the melting point of lithium (459 K) (figure 2 ) are identified (Grow and Pitzer 1977; Andrews and Smardzewski 1973; Thirumalavan and Kumar 1986) and are given in table 1. It is found that as temperature increases the intensity of lines also increases but the peak intensity decreases from 478 to $508 \mathrm{~K}$. This comparison from the table indicates the formation of more oxides at 


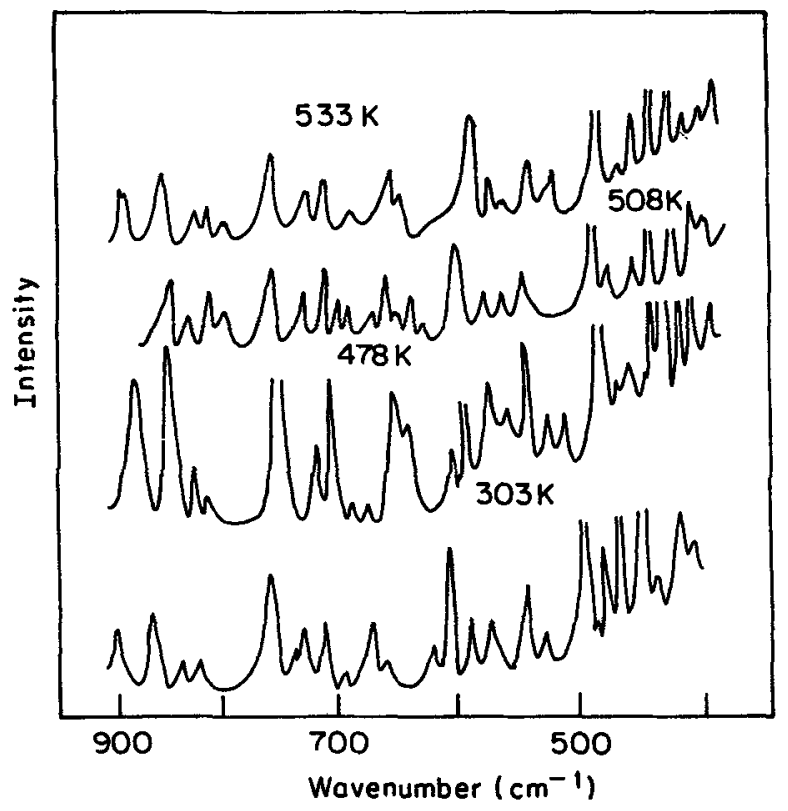

Figure 2. Reflectance Raman spectra of oxidized Al(Li) alloy films at 303, 478, 508 and $533 \mathrm{~K}$.

Table 1. Raman frequencies of oxidised Al(Li) thin films.

Raman frequency $\left(\mathrm{cm}^{-1}\right)$

at

\begin{tabular}{lcccl}
$303 \mathrm{~K}$ & $478 \mathrm{~K}$ & $508 \mathrm{~K}$ & $533 \mathrm{~K}$ & \multicolumn{1}{l}{ Identification } \\
\hline 411 & 411 & 410 & 410 & $\mathrm{Al}_{2} \mathrm{O}_{3}$ \\
440 & 440 & 440 & 440 & $\mathrm{Al}_{2} \mathrm{O}_{3}$ \\
451 & 448 & 449 & 450 & $\mathrm{Al}_{2} \mathrm{O}_{3}$ \\
460 & 460 & 458 & 462 & $\mathrm{Al}_{2} \mathrm{O}_{3}$ \\
495 & 495 & 495 & 495 & $\mathrm{LiO}_{2}$ \\
500 & 500 & 500 & 500 & $\mathrm{LiO}_{2}$ \\
545 & 545 & 545 & 530 & $?$ \\
555 & 555 & 555 & 555 & $?$ \\
570 & 570 & 570 & 572 & $\mathrm{Al}_{2} \mathrm{O}_{3}$ \\
595 & 595 & 595 & 595 & $?$ \\
610 & 610 & 610 & 610 & $\mathrm{Al}_{2} \mathrm{O}_{3}$ \\
675 & 675 & 675 & 678 & $\mathrm{Al}-\mathrm{O}$ vibration \\
\hline 710 & 700 & 700 & 705 & $\mathrm{LiO}_{2}$ \\
740 & 740 & 740 & 740 & $\mathrm{LiO}$ vibration \\
750 & 750 & 750 & 750 & $\mathrm{AlO}_{2}$ \\
770 & 770 & 770 & 770 & $\mathrm{Li}_{2} \mathrm{O}$ \\
825 & 815 & 825 & 810 & $\mathrm{Li}_{2} \mathrm{O}$ \\
\hline
\end{tabular}

higher temperature. Also the peaks get broadened as temperature increases and as grain size decreases (Fauchet 1985). The discrepancy in intensity variation at 
temperatures 478 to $508 \mathrm{~K}$ is attributed to the protective scaling of the polycrystalline aluminium oxides.

At room temperature, the oxides formed on the films are $\mathrm{Li}_{2} \mathrm{O}, \mathrm{LiO}_{2}, \mathrm{Al}_{2} \mathrm{O}_{3}$ and $\mathrm{AlO}_{2}$, the more probable ones being $\mathrm{Al}_{2} \mathrm{O}_{3}$ and $\mathrm{LiO}_{2}$. The concentration of $\mathrm{LiO}_{2}$ is found to increase with increase in temperature. Also, thermochemical data indicate that the formation of $\mathrm{Li}_{2} \mathrm{O}$ is more probable than $\mathrm{LiO}$ in an alloy (Hildenbrand 1972).

\section{Conclusions}

The oxidation of Al-2 wt \% Li alloy thin films (thickness $\sim 10 \mathrm{~nm}$ ) prepared by vacuum evaporation on clean glass substrates is found to obey the logarithmic rate law of oxide growth as in the case of pure aluminium films but with higher rates of oxidation. Laser Raman surface studies show that the more probable oxides are $\mathrm{Al}_{2} \mathrm{O}_{3}$ and $\mathrm{LiO}_{2}$.

\section{Acknowledgement}

The authors are thankful to the State Committee on Science, Technology and Environment, Kerala State, for financial assistance; and to Mr Xavier Mathew for recording the spectra. One of the authors (VG) is grateful to the Council of Scientific and Industrial Research, New Delhi, for the award of a fellowship.

\section{References}

Ando K, Akiyama M and Oishi Y 1986 J. Nucl. Mater. 95257

Andrews L and Smardzewski R 1973 J. Chem. Phys. 62258

Bhavani K and Vaidyan V K 1979 Natl. Acad. Sci. Lett. 2457

Fauchel P M 1985 Proc. In Beam Solid Interactions and Phase transformations, (Pittsburgh: Mater. Res. Soc.) p 149

Grow T D and Pitzer M R 1977 J. Chem. Phys. 674019

Hildenbrand D L 1972 J. Chem. Phys. 574556

Kishio K, Owers Bradley J R, Halperin W P and Britain Jao 1981 J. Phys. Chem. Solids 421031

Kurtasova L A and Polyanskii V M 1983 Sov. Mater. Sci. (Engl. Transl.) 19103

Thirumalavan M and Kumar 1986 Infrared Phys. 26101

Wallwork G R 1976 Rep. Prog. Phys. 39401 